\title{
Impending paradoxical embolism with a thrombus crossing a patent foramen ovale
}

\author{
Ana Faustino, Gisela Costa, Rui Providência, Luis Paiva \\ Cardiology Department, Coimbra's Hospital Centre and University, Coimbra, Portugal
}

Correspondence to Dr Rui Providência,rui_providencia@yahoo.com

\section{DESCRIPTION}

A 42-year-old female with a history of migraine was admitted to our hospital with syncope at rest. She had a 1-week history of dizziness, fatigue, headache and right lower limb pain. At physical examination she had a body mass index of $33.6 \mathrm{~kg} / \mathrm{m}^{2}$, oedema of the right lower limb, and her blood pressure was $100 / 69 \mathrm{~mm} \mathrm{Hg}$, with $95 \%$ oxygen saturation. Troponin I was $0.1 \mathrm{ng} / \mathrm{ml}$ (normal $<0.034 \mathrm{ng} / \mathrm{ml}$ ) and NT-proBNP was $5260 \mathrm{pg} / \mathrm{ml}$ (normal $<1800 \mathrm{pg} / \mathrm{ml}$ ). An ECG showed sinus tachycardia with $110 \mathrm{bpm}$ and negative $\mathrm{T}$-waves in inferior and anterior leads. A Doppler ultrasound of the right lower limb confirmed the diagnosis of deep venous thrombosis. A transthoracic echocardiography documented a very mobile, irregular, heterogeneous and huge $(1 \mathrm{~cm} \times 1.8 \mathrm{~cm})$ mass in the right atria crossing the interatrial septum and intermittently the mitral valve, swinging between the left atria and left ventricle (videos 1-3). There was also a heterogeneous mass in the right branch of the pulmonary artery, enlargement and hypokinesia of the right ventricle, interventricular septal rectification, moderate tricuspid regurgitation and an estimated pulmonary artery systolic pressure of $83 \mathrm{~mm} \mathrm{Hg}$ (figures 1 and 2). A chest CT scan confirmed bilateral pulmonary thromboembolism (figure 3). Perfusion of alteplase was started but was discontinued after half the dosage $(50 \mathrm{mg}$ ) owing to a massive haematoma of the neck with dysphagia. After consulting a thoracic surgeon, a continuous infusion of unfractionated heparin

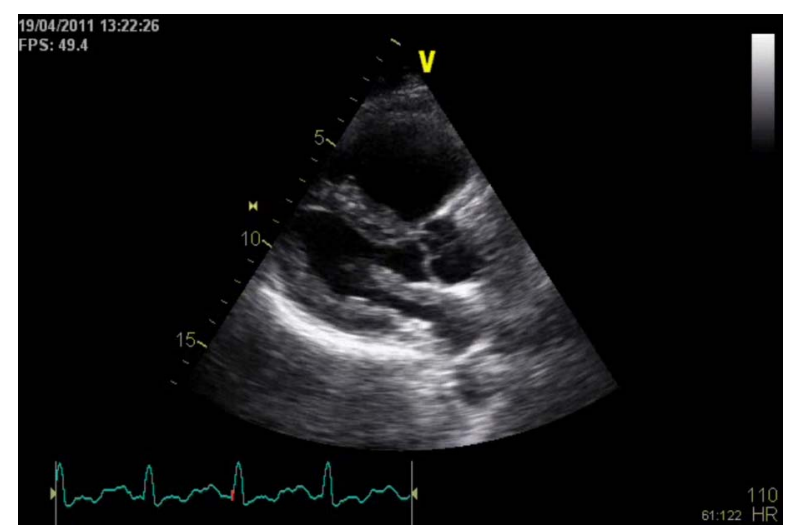

Video 1 Transthoracic echocardiogram parasternal long-axis view-thrombus attached to the septal part of the left atrium and crossing the mitral valve during diastole.

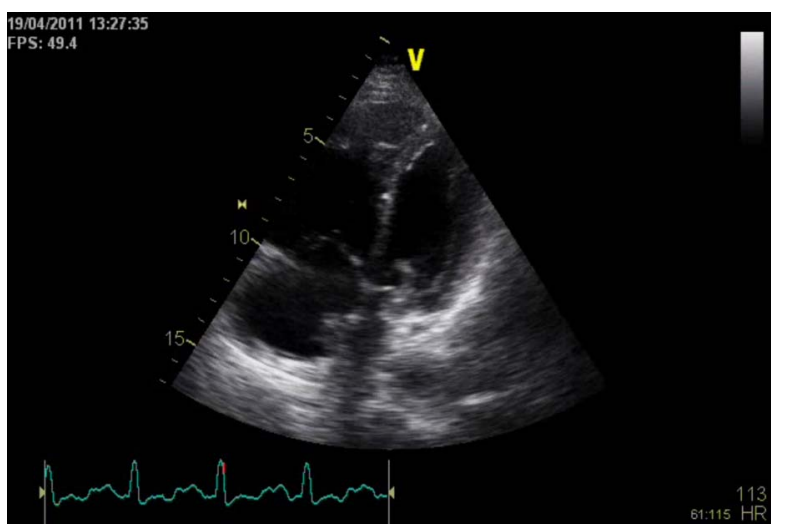

Video 2 Transthoracic echocardiogram apical four-chamber view-here the attachment of the thrombus, crossing the atrial septum from the right atrium into the left atrium, can be more clearly spotted. Severe dilation of the right atrium and ventricle can also be clearly seen.

was started, with a complete resolution of the mass in 3 days (confirmed on transesophageal echocardiogram). As the patient complained of a severe and persistent migrainelike headache, a cranial magnetic resonance was performed 14 days after the admission to rule out paradoxical embolism or treatment-related intracranial bleeding (figure 4). The examination showed small high-signal foci in the supratentorial white matter compatible with multiple small strokes. The serological screening carried out for thrombophilia,

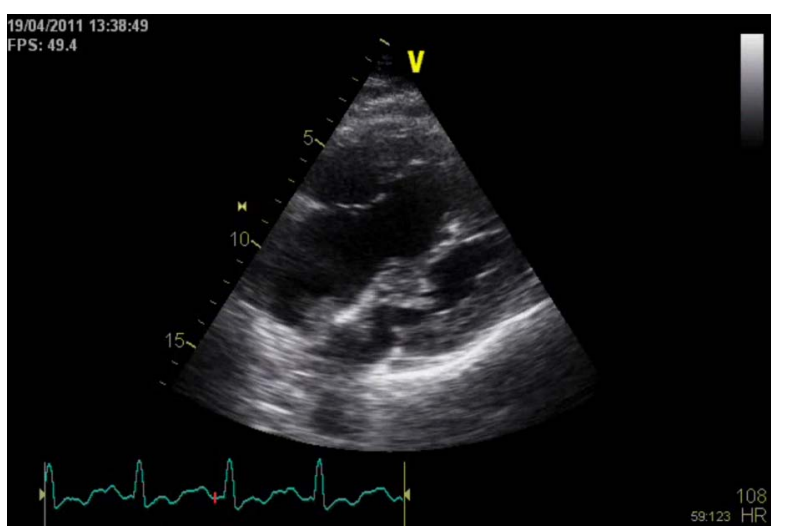

Video 3 Same as the previous movie, but a subcostal view. 


\section{BMJ Case Reports}

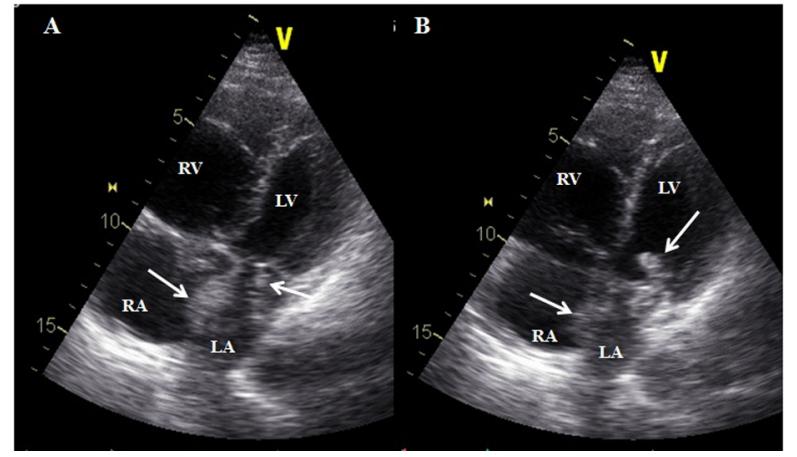

Figure 1 Transthoracic echocardiography performed in the emergency room, in a four-chamber view, showing the thrombus on both sides of the interatrial septum (A) and crossing the mitral valve during diastole (B). RV, right ventricle; $L V$, left ventricle; $R A$, right atria; LA, left atria; the arrows indicate the thrombus.

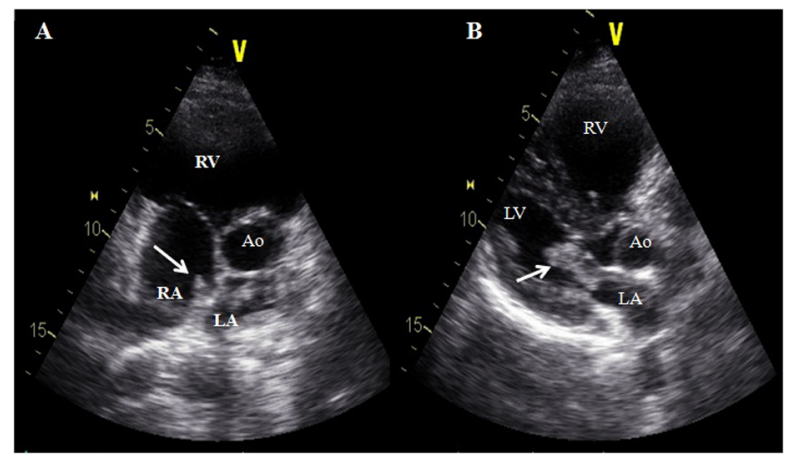

Figure 2 Transthoracic echocardiography performed in the emergency room. (A) In a longitudinal short-axis view demonstrating the thrombus on both sides of the interatrial septum; (B) In a longitudinal long-axis view showing the thrombus crossing the mitral valve in diastole $(B) . R V$, right ventricle; $L V$, left ventricle; $R A$, right atria; $L A$, left atria; $A o$, aorta; the arrows indicate the thrombus.

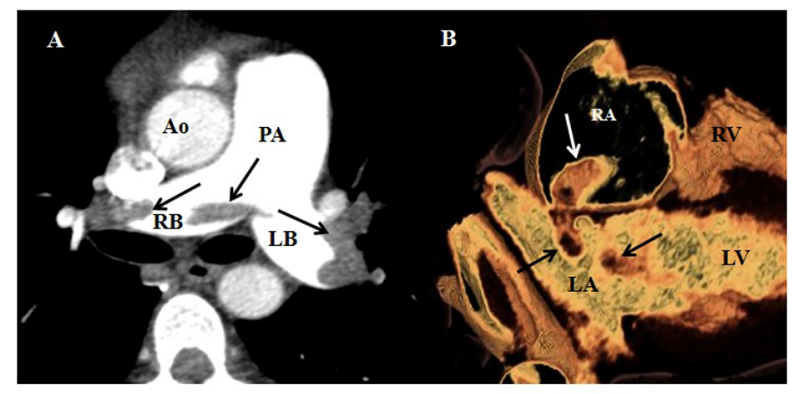

Figure 3 Chest angio-CT scan obtained $3 \mathrm{~h}$ after the admission. (A) In an axial plane, identifying a filling defect in both branches of the pulmonary artery, confirming a diagnosis of pulmonary embolism; (B) In a volume-rendered endocardial view, showing the thrombus through the suspected defect in the interatrial septum. Ao, aorta; PA, pulmonary artery; RB, right branch; LB, left branch; $R V$, right ventricle, $L V$, left ventricle; $R A$, right atria; $L A$, left atria; the arrows indicate the thrombus.

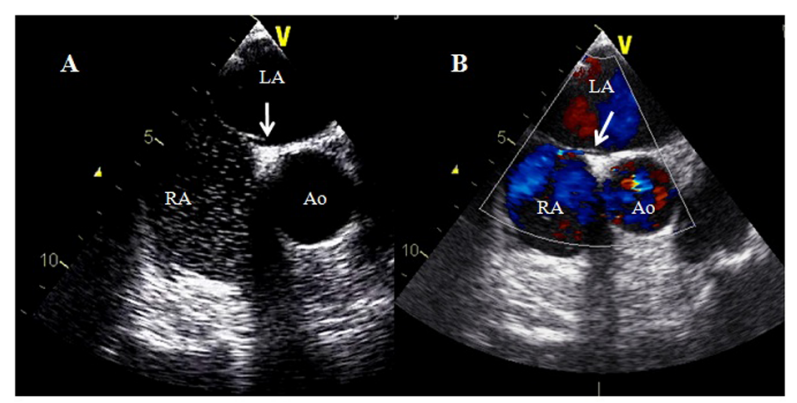

Figure 4 Transesophageal echocardiography performed 15 days after the admission, obtained at $55^{\circ}$, confirming the presence of a patent foramen ovale. (A) During the microbubbles test; (B) With colour doppler. Ao, aorta; LA, left atria; RA, right atria; the arrow indicates the patent foramen ovale.

autoimmune diseases and vasculitis was negative. The patient was discharged without any neurological deficits after percutaneous closure of the patent foramen ovale under hypocoagulation.

Learning points

Acute pulmonary embolism and impending paradoxical embolism are two conditions with a high risk of mortality.

- Surgical embolectomy has been proposed as the treatment of choice because it seems to be associated with lower systemic embolism, but did not significantly reduce mortality compared with thrombolysis or anticoagulation. ${ }^{12}$

- This case illustrates the possibility of success and the risks of thrombolysis: this patient recovered completely but developed a neck haematoma.

- Paradoxical embolism may be an indication for a percutaneous closure of the patent foramen ovale.

Competing interests None.

Patient consent Obtained.

\section{REFERENCES}

1. Myers PO, Bounameaux H, Panos A, et al. Impending paradoxical embolism: systematic review of prognostic factors and treatment. Chest 2010;137:164-70.

2. Torbicki A, Camm J, Caterina R, et al. Guidelines on the diagnosis and management of acute pulmonary embolism. Eur Heart J 2008;29:2276-315. 
Copyright 2012 BMJ Publishing Group. All rights reserved. For permission to reuse any of this content visit http://group.bmj.com/group/rights-licensing/permissions.

BMJ Case Report Fellows may re-use this article for personal use and teaching without any further permission.

Please cite this article as follows (you will need to access the article online to obtain the date of publication).

Faustino A, Costa G, Providência R, Paiva L. Impending paradoxical embolism with a thrombus crossing a patent foramen ovale. BMJ Case Reports 2012;10.1136/bcr-2012-006662, Published XXX

Become a Fellow of BMJ Case Reports today and you can:

- Submit as many cases as you like

- Enjoy fast sympathetic peer review and rapid publication of accepted articles

- Access all the published articles

- Re-use any of the published material for personal use and teaching without further permission

For information on Institutional Fellowships contact consortiasales@bmjgroup.com

Visit casereports.bmj.com for more articles like this and to become a Fellow 